\title{
Acquired cerebellar ataxia due to statin use
}

\section{Ataxia cerebelar adquirida devido ao uso de estatina}

\author{
Hélio A. G. Teive, Renato Puppi Munhoz, Lineu César Werneck
}

Movement Disorders Unit, Neurology Service, Internal Medicine Department, Hospital de Clínicas, Federal University of Paraná, Curitiba PR, Brazil. Correspondence: Hélio A. G. Teive; Neurology Service, Federal University of Paraná; Rua General Carneiro 1103 / 102; 80060 -150 Curitiba PR - Brasil; E-mail: hagteive@mps.com.br

Conflict of interest There is no conflict of interest to declare.

Received 22 October 2011; Received in final form 03 November 2011; Accepted 10 November 2011

Acquired or secondary cerebellar ataxias are chronic diseases of the cerebellum, due to exogenous or endogenous nongenetic causes ${ }^{1}$. The most common secondary cerebellar ataxias are those caused by toxicity, including alcoholic cerebellar degeneration and drug induced (e.g., lithium, phenytoin, toluene, and anticancer drugs); immune-mediated ataxias, including paraneoplastic cerebellar degeneration, ataxia associated with celiac disease (gluten ataxia) and ataxia with glutamic acid decarboxylase antibodies (anti-GAD); and ataxias caused by vitamin deficiencies (vitamins B1, B12, and E) ${ }^{1}$.

We reported the case of a patient who developed progressive cerebellar ataxia induced by hydroxyl-3-methylglutary1coenzymeA (HMG-CoA) reductase inhibitor. A 52-year-old male, presented with slowly progressive gait ataxia starting one month previous to his first examination. His previous medical history was positive for dyslipidemia (most recent total cholesterol $=254 \mathrm{mg} / \mathrm{dL}, \mathrm{LDL}=150 \mathrm{mg} / \mathrm{dL}$ and $\mathrm{HDL}=40 \mathrm{mg} / \mathrm{dL}$ ), using atorvastatin calcium for the previous three-months (10 mg qd). General physical examination was normal, and neurological examination revealed the presence of gait ataxia in tandem gait. Ocular motility was normal, with no nystagmus, although the patient reported oscillopsia after fast head movements in different directions.

The total scale for the assessment and rating ataxia (SARA) score was 2. An extensive complementary investigation was carried out, including brain magnetic resonance imaging; brain and cervical magnetic resonance angiography; complete blood count, erythrocyte sedimentation rate, C-reactive protein, creatinine, TSH, T3, T4, VDRL and liver enzymes; and anti-HIV, anti-thyroglobulin, anti-gliadin, anti-GAD and thyroid peroxidase antibodies. All yielded normal results. Blood glucose was
$112 \mathrm{mg} / \mathrm{dL}$ ( $85 \mathrm{mg} / \mathrm{dL}$ when measured three months previously) and CPK was $214 \mathrm{U} / \mathrm{L}$ (normal value up to $200 \mathrm{U} / \mathrm{L}$ ).

After the HMG-CoA reductase inhibitor was withdrawn, there was a progressive and complete improvement in the gait ataxia, including the complaint of oscillopsia after 30 days (SARA scale $=0$ ). Complementary tests carried out three months after the drug had been discontinued showed blood glucose of $85 \mathrm{mg} / \mathrm{dL}$ and total cholesterol of $230 \mathrm{mg} / \mathrm{dL}$, $\mathrm{LDL}=140 \mathrm{mg} / \mathrm{dL}$ and $\mathrm{HDL}=40 \mathrm{mg} / \mathrm{dL}$. The patient was started using atorvastatin again and reported gait ataxia after two months. The medication was then suspended indefinitely.

Statins, or HMG-CoA reductase inhibitors, are cholesterol-lowering drugs that reduce morbidity and mortality in patients with cardiovascular disease ${ }^{2}$. In general, statin use results in greater nitric oxide bioavailability, improved endothelial function, enhanced cerebral blood flow, immune modulation with anti-inflammatory effect, decreased platelet aggregation, and antioxidant activity ${ }^{2}$.The most common complication of statin use is myopathy, ranging from painless creatine kinase elevations and myalgias to rhabdomyolysis ${ }^{3}$. Different mechanisms have been proposed to explain statin-induced-myopathy, including mitochondrial dysfunction, genetic predisposition, induction of apoptosis, and reduction in mevalonate pathway products, leading to a decrease in coenzyme Q10 levels ${ }^{3}$.More recently, risk of incident diabetes mellitus and statin use have been associated ${ }^{4}$.In this case report, a patient developed cerebellar ataxia and oscillopsia with mild hyperglycemia following statin use. To our knowledge, an association between statin use and secondary cerebellar ataxia has not been described in the literature to date. Coenzyme Q10 deficiency is associated with cerebellar ataxia and could be a possible link between statin use and the development of this condition ${ }^{5}$.

\section{References}

1. Klockgether T. Acquired cerebellar ataxias and differential diagnosis. In: Brice A, Pulst SM. Spinocerebellar degenerations. The ataxias and spastic paraplegias. Philadelphia, PA: Butterworth Heinemannn Elsevier; 2007:61-77. neurological disorders: progress to date. Drugs 2007;67:2111-2120. with exercise. Muscle Nerve 2010;42:469-479.

4. Preiss D, Seshasai SR, Welsh P, et al. Risk of incident diabetes with intensive-dose compared with moderate-dose statin therapy: a metaanalysis. JAMA 2011;305:2556-2564.

5. Musumeci O, Naini A, Slonim AE, Skavin N, Hadjigeorgiou GL, Krawiecki N, et al. Familial cerebellar ataxia with muscle coenzyme Q10 deficiency. Neurology 2001;56:849-855. 